\title{
Reassortant Highly Pathogenic H5N6 Avian Influenza Virus Containing Low Pathogenic Viral Genes in a Local Live Poultry Market, Vietnam
}

\author{
Tran Bac Le ${ }^{1,2} \cdot$ Van Phan Le ${ }^{3} \cdot$ Ji-Eun Lee ${ }^{1,2} \cdot$ Jung-Ah Kang ${ }^{2} \cdot$ Thi Bich Ngoc Trinh $^{3} \cdot$ Hyeok Won Lee ${ }^{4}$ \\ Dae Gwin Jeong ${ }^{1,2} \cdot$ Sun-Woo Yoon ${ }^{1,2}$
}

Received: 21 April 2021 / Accepted: 8 September 2021 / Published online: 21 September 2021

(c) The Author(s) 2021

\begin{abstract}
Sites of live poultry trade and marketing are hot spots for avian influenza virus (AIV) transmission. We conducted active surveillance at a local live poultry market (LPM) in northern Vietnamese provinces in December 2016. Feces samples from the market were collected and tested for AIV. A new reassorted AIV strain was isolated from female chickens, named A/ chicken/Vietnam/AI-1606/2016 (H5N6), and was found to belong to group C of clade 2.3.4.4 H5N6 highly pathogenic (HP) AIVs. The neuraminidase gene belongs to the reassortant B type. The viral genome also contained polymerase basic 2 and polymerase acidic, which were most closely related to domestic-duck-origin low pathogenic AIVs in Japan (H3N8) and Mongolia (H4N6). The other six genes were most closely related to poultry-origin H5N6 HP AIVs in Vietnam and had over 97\% sequence identity with human AIV isolate A/Guangzhou/39715/2014 (H5N6). The new reassorted AIV isolate A/chicken/Vietnam/AI-1606/2016 (H5N6) identified in this study exemplifies AIVs reassortment and evolution through contact among wild birds, poultry farms, and LPMs. Therefore, active surveillance of AIVs is necessary to prevent potential threats to human and animal health.
\end{abstract}

\section{Introduction}

Avian influenza viruses (AIVs) belong to the family Orthomyxoviridae. Among the AIV subtypes identified in wild aquatic birds based on two surface glycoproteins, hemagglutinin (HA1 to 16) and neuraminidase (NA1 to 9), H5Nx subtypes have been a major concern in the poultry industry and public health since the first highly pathogenic avian influenza virus (HPAIV) H5N1 subtype was detected in a goose in Guangdong (Gs/GD) province, China, $1996[1,2]$.

Dae Gwin Jeong

dgjeong@kribb.re.kr

Sun-Woo Yoon

syoon@kribb.re.kr

1 Bio-Nanotechnologytechnology Research Center, Korea Research Institute of Bioscience and Biotechnology, Daejeon 34141, South Korea

2 Bio-Analytical Science Division, University of Science and Technology, Daejeon 34113, South Korea

3 College of Veterinary Medicine, Vietnam National University of Agriculture, Hanoi 100000, Vietnam

4 Bio-Process Engineering Center, Korea Research Institute of Bioscience and Biotechnology, Daejeon 34141, Korea
Based on their pathogenicity in chickens and the multi-basic cleavage site motif in the HA protein, H5Nx subtypes have both low pathogenic (LP) and HPAIV types [3]. Aquatic birds, being the major natural reservoir of AIVs, are subject to natural migration and factitious trading in live poultry markets (LPMs). Interaction among them through the intersection of wild birds and poultry sector, together with the specialized genome organization of AIVs, these factors have created numerous clades of H5 HPAIV and reassortant strains, which are variants differing in NA subtypes, such as H5N1, H5N2, H5N5, H5N6, and H5N8. These strains, along with variants originating from other internal genes, have caused outbreaks in poultry in over 80 countries worldwide, including China, Japan, South Korea, Laos, and Vietnam thus far [4].

In 2013, the first clade 2.3.4.4 H5N6 HPAIV was identified and was the result of a reassortant between the HPAIV H5N1 subtype and LPAIV H6N6, which circulate broadly in duck populations in southern and eastern China [5]. Reassortants with six internal genes such as PB2, PB1, PA, NP, M, and NS in H5N6 from the chicken H9N2 or H7N9 gene pool, have also been reported [6]. As of May 2020, 24 human cases of H5N6 HPAIV infection have occurred exclusively in China since 2014, and a mortality rate of $\sim 66 \%(16 / 24)$ 
was reported by the World Health Organization (WHO) [7]. Occasionally, H5N6 HPAI viruses have also been detected in mammals such as pigs and domestic cats [8,9]. Swine have been considered for intermediate transmission of influenza A viruses between birds and humans because they have both $\alpha 2,6-$ and $\alpha 2,3$-linked sialic acid receptors [1].

In Vietnam, the first Gs/GD lineage H5N1 HPAIV was detected in 2001 [10], and numerous clades have been identified since then [11-14]. Clade 1 was the primary cause of the first wave of massive outbreaks in poultry during 2003-2005 and was subsequently replaced by other clades, such as clade 2.3.2 in 2005-2008 and 2.3.4 in 2007-2010 in the North and Central regions. Clade 1 and its descendants, including clade 1.1.1 and 1.1.2, continued to predominate in the South region. Clade 2.3.2.1 (a/b/c) replaced clade 2.3.4 in parts of the North and Central regions beginning in 2009, and clade 2.3.2.1c spread to the South region after 2012. Since 2014, clades 2.3.2.1c and 2.3.4.4 have become concurrently predominant in Vietnam.

LPMs are integral components of the poultry trade network in Vietnam. The behavior of poultry traders in Vietnamese markets is a potential risk factor for human and animal health, making it more likely for AIVs to overcome the species barrier [15]. Hence, enhanced surveillance activity and complete viral genetic analyses are necessary for virus tracing and maintenance of human and animal health. In this report, we isolated and genetically characterized a new reassortant clade 2.3.4.4 group C H5N6 HPAIV strain from female chicken feces collected from LPMs in northern Vietnamese provinces in December 2016. Our findings have extended our understanding of H5N6 HPAIV genetic diversity in poultry and how the trading network in Vietnam affects AIV evolution.

\section{Materials and Methods}

During the winter between 2016 and 2017, feces sampling in poultry was carried out at local LPMs and small-scale poultry farms in Ha Nam province, Vietnam (approximately $60 \mathrm{~km}$ from Hanoi to the south). A total 353 of fecal, tracheal, and cloacal swab samples were collected from four local live bird markets and poultry farms and plated into transportation medium (Noble Biosciences, South Korea) and stored at $-80^{\circ} \mathrm{C}$. Samples were then tested for AIVs using a matrix $(\mathrm{M})$ gene-specific real-time reverse transcription quantitative polymerase chain reaction (RT-qPCR) method according to the WHO guideline for animal influenza virus detection [16]. Continuously, the samples containing influenza A virus were examined for HPAIV and clade detection based on an RT-qPCR assay following a previous report [17]. Positive AIV samples were isolated by inoculating 10-day-old embryonated chicken eggs in a biosafety level two plus facility at the College of Veterinary Medicine, Vietnam National University of Agriculture, Hanoi, Vietnam. The host sex and species was determined by analyzing the mitochondrial cytochrome oxidase (COI) and chromo-domain helicase DNA binding (CHD) genes following a previous report $[18,19]$.

For complete viral genome analysis of the new isolate, viral RNA was prepared from the allantoic fluid from the first egg passage using a QIAamp Viral RNA Mini Kit (Qiagen, CA, USA) following the manufacturer's protocol. Viral genome amplification was performed using the conventional RT-PCR method with PrimeScript ${ }^{\mathrm{TM}}$ First-Strand cDNA Synthesis Kit and Premix Taq ${ }^{\mathrm{TM}}$ (Takara, Japan) with universal primers previously described [20]. The DNA band for each target gene was excised from a $1 \%$ agarose gel and DNA was purified using the QIAquick Gel Extraction Kit (Qiagen, CA, USA). The purified DNA was then subjected to direct sequencing using an ABI3730XL DNA analyzer (Cosmo Genetech Service, South Korea). The sequences were assembled using CLC Sequence Viewer software version 6.7. Non-coding regions containing primer sequences were trimmed. The open reading frames of eight genes were submitted to GenBank under accession number MT634255MT634262. A BLAST search on the GenBank database was used to determine the closest related strains to the newly isolated virus.

Phylogenetic analysis based on each gene sequence was conducted using Molecular Evolutionary Genetics Analysis Version 7.0 software (MEGA 7.0). The evolutionary distances were computed using the Maximum Composite Likelihood method with 1000 replicates. Input nucleotide sequences included both the new isolate and reference sequences from the open access resources for the GenBank database of influenza virus. The length of eight segments containing the PB2, PB1, PA, HA, NP, NA, M, and NS genes used for phylogenetic analysis were 2280, 2274, 2151, 1704, 1497, 1380, 982, and 823 nucleotides, respectively.

\section{Results}

Among the eight confirmed positive samples of influenza A virus by M-gene-specific RT-qPCR, we identified three of H5N1 and four of H9N2 avian influenza viruses (Supplementary Table 1). Interestingly, a fecal sample collected from a local LPM on December 30th, 2016 was suspected to be positive for HPAIV. In the first egg passage, the isolate showed signs of HPAI virus infection, such as death of the embryos and allantoic fluid in red at $36 \mathrm{~h}$ post-inoculation. The new reassortant strain of clade 2.3.4.4c H5N6 HPAIV was identified and named A/Chicken/Vietnam/AI-1606/2016 (abbreviated as A/AI-1606/16). The geographical location of the A/AI-1606/16 isolate was shown in Fig. 1. A female 

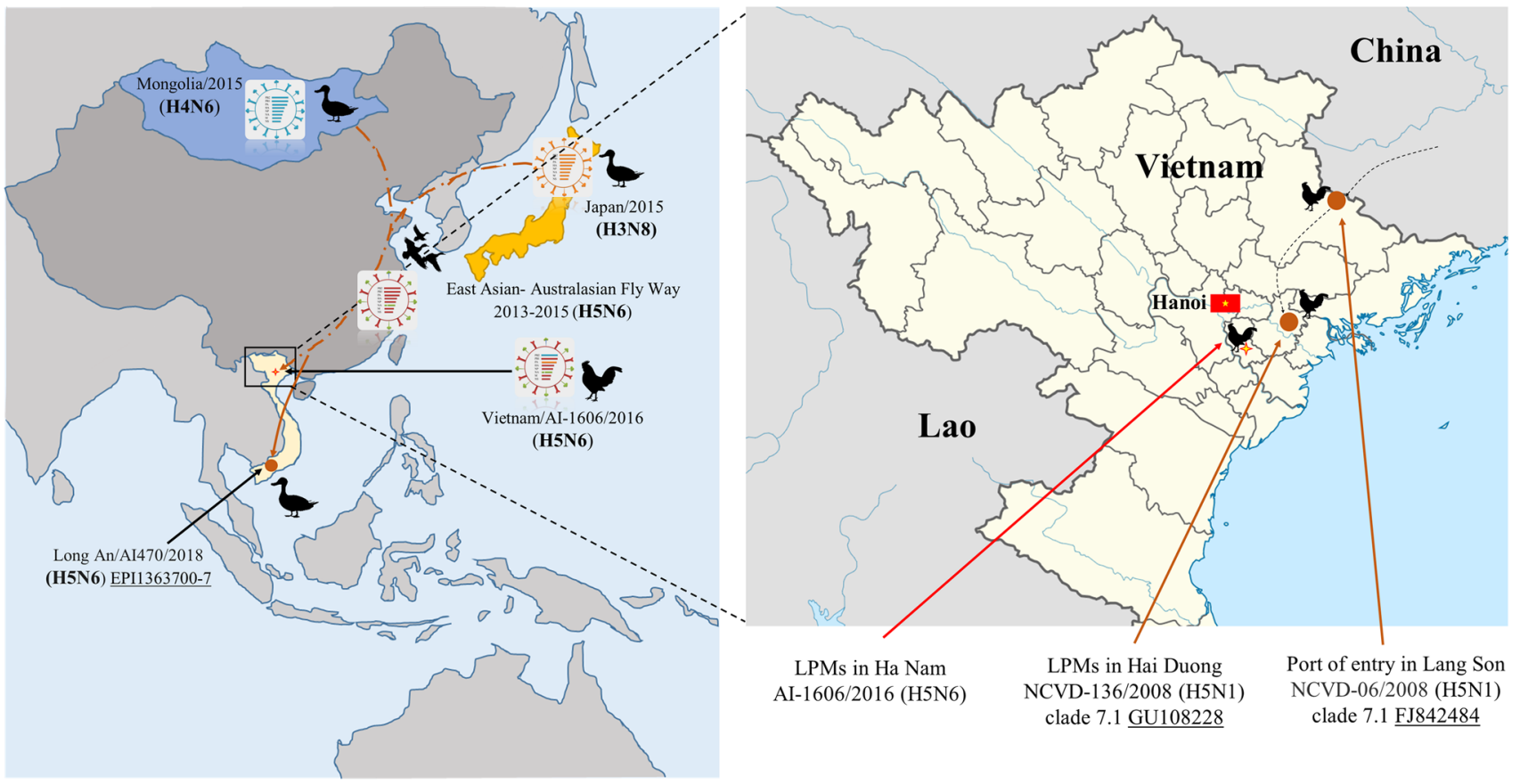

Fig. 1 Location of putative origins of genomic compositions of the new reassortant A/chicken/Vietnam/AI-1606/2016 (H5N6). The brown circles were isolates in previous reports and red arrows were reassortant A/chicken/Vietnam/AI-1606/2016 isolate in this report

chicken (Gallus gallus) was the host of A/AI-1606/16 followed to COI and CHD partial genes analysis (Supplementary Fig. 1).

Based on the genetic analysis, suggested that the A/ AI-1606/16 isolate was closely related to domestic-poultry-origin AIVs. The six segments of PB1, HA, NP, NA, $\mathrm{M}$, and NS genes were most closely related to the H5N6 HPAIV virus that circulated among domestic poultry in Vietnam between 2015 and 2016. The sequence similarity was greater than $99 \%$. However, the PB2 gene was most closely related to A/duck/Mongolia/543/2015(H4N6), with 98.82\% identity; and the PA gene was most closely related to A/duck/Hokkaido/20/2015 (H3N8), with $98.84 \%$ identity. The closest similarities of the eight gene segments of the $\mathrm{A} /$ AI-1606/16 virus are listed in Table 1, and Fig. 2I shows how the virus may have been generated.

In the phylogenetic tree analysis, the eight genes of the A/AI-1606/16 virus belonged to Eurasian lineages (Fig. 2A-H). The HA gene fell into group $\mathrm{C}$ of clade 2.3.4.4, the NA gene grouped into reassortant $\mathrm{B}$ type, and the PB2 and PA genes associated with LPAIVs; domestic ducks in Mongolia (H4N6) and Japan (H3N8), respectively. The NS gene belonged to allele A.

The predicted amino acid sequence of the A/AI-1606/16 viral genome was analyzed to better understand the new isolate, and specific regions of the A/AI-1606/16 viral genome were examined (Table 1). The HA protein contains PLRERRRKR $\downarrow$ GLF at the cleavage site, indicating a highly pathogenic phenotype. The virus harbors two conserved amino acid residues in the receptor-binding site of the HA protein (Q226 and G228), suggesting preference for avian-like receptors. Remarkably, the substitutions H107Y, S137A, and T160A were detected in the isolated virus, indicating humanlike receptor recognition and the possibility of transmissibility in ferrets [8]. The NA protein contains an 11 amino acid deletion (59-69) in the stalk region, promoting adaptation and enhancing virulence toward poultry and mammals [8]. The NS1 protein contains a five amino acid deletions (80-84), suggesting increased virulence in chickens and mice [27]. Similar to mouse models that have identified substitutions associated with increased viral pathogenicity and replication, substitutions have been detected in the isolated virus in the PB2 protein (L89V, G309D, T339K, R447G, and I495V), M1 protein (N30D and T215A), and NS1 protein (P42S, D92E, and PDZmotif ESEV) [8]. The molecular markers of NA inhibitors (oseltamivir and zanamivir) [22] and ion-channel inhibitors (amantadine and rimantadine) $[26,28]$ in the NA and M2 proteins of the A/AI-1606/16 virus exhibited no mutations, suggesting susceptibility to these antiviral influenza drugs.

\section{Discussion}

Clade 2.3.4.4 H5N6 HPAIVs have evolved and been reassorted from Gs/GD since 2013. Based on the HA gene, the clade was clustered into four groups, A, B, C, and D, among 
which group $\mathrm{C}$ is predominant and has been disseminated in Asia and Southeast Asian countries such as China, Vietnam, and Laos [4]. Most prior instances of human H5N6 infections have been from viruses in group $C$ [21]. There are two types of NA genes, reassortant A (no amino acid deletion) and B (an 11 amino acid deletion from 59 to 69 in the stalk region) [29]. Here, in the newly isolated virus, phylogenetic analysis of A/AI-1606/16 revealed that six out of eight genes were most closely related to the H5N6 HPAIV, which has a domestic-poultry-origin in Vietnam between 2015 and 2016. The new isolate also fell into group $\mathrm{C}$ and shared over $97 \%$ identity with the human isolate A/ Guangzhou/39715/2014(H5N6). The NA gene belongs to the reassortant B type. Interestingly, the PB2 and PA genes were closely related to LPAIV strains from domestic ducks in Mongolia (H4N6) and Japan (H3N8), respectively.
Fig. 2 Phylogenetic and genotype illustration analysis of A/chicken/ Vietnam/AI-1606/2016 (H5N6) virus. Phylogenetic tree based on nucleotide sequences of eight genes $(\mathbf{A}-\mathbf{H})$ were conducted using Molecular Evolutionary Genetics Analysis Version 7.0. The evolutionary distances were computed using the Maximum Composite Likelihood method with 1000 replicates. The input nucleotide sequences included both new isolate and reference sequences obtained from the influenza virus resource at the National Center for Biotechnology Information (NCBI). The statistic values greater than $70 \%$ a measure of reliability from a bootstrap $(n=1000)$ iterations were showed. Genotype illustration (I) of the new reassortant A/ chicken/Vietnam/AI-1606/2016 (H5N6)

The 2.3.4.4 H5N6 HPAI virus was detected in Vietnam immediately after its initial detection in China in 2013 [13]. Nguyen et al. [30] showed that in the period from 2014 to 2017, two predominant clades of H5 HPAI viruses, 2.3.2.1c and 2.3.4.4, evolved from homologous clade viruses endemic

Table 1 Closest related viruses and identification of amino acids deduction of A/chicken/Vietnam/AI-1606/2016 (H5N6) isolate involved in binding to human-type influenza receptor, enhancing antiviral drug resistance, and causing pathogenesis in mammals

\begin{tabular}{|c|c|c|c|c|}
\hline Top BLAST H5N6 HPAI strains & & Viral protein* & & $\begin{array}{l}\text { Molecular and phenotypic impact of amino acid } \\
\text { [reference] }\end{array}$ \\
\hline \multirow[t]{4}{*}{ A/chicken/Quang Tri/MT11/2016 (H5N6) } & \multirow[t]{4}{*}{ HA } & PLRERRRKR $\downarrow G L F$ & Cleavage site & $\begin{array}{l}\text { Expanded viral tropism; increased virulence in } \\
\text { mice [8] }\end{array}$ \\
\hline & & $107 \mathrm{Y}$ & $\mathrm{H} \rightarrow \mathrm{Y}$ & H5 transmissibility in ferrets [8] \\
\hline & & $137 \mathrm{~A}$ & $\mathrm{~S} \rightarrow \mathrm{A}$ & Increased $\alpha 2,6-\mathrm{SA}$ recognition [21] \\
\hline & & $160 \mathrm{~A}$ & $\mathrm{~T} \rightarrow \mathrm{A}$ & H5 transmissibility in ferrets [8] \\
\hline \multirow{3}{*}{$\begin{array}{l}\text { A/chicken/Vietnam/NCVD-15A51/2015 } \\
\text { (H5N6) }\end{array}$} & \multirow[t]{3}{*}{ NA } & $59 \rightarrow 69$ deletion & Stalk region & Increased virulence in mice [8] \\
\hline & & $274 \mathrm{H}$ & $\mathrm{H} \rightarrow \mathrm{Y}$ & Oseltamivir resistance [22] \\
\hline & & $294 \mathrm{~N}$ & $\mathrm{~N} \rightarrow \mathrm{S}$ & Oseltamivir resistance [22] \\
\hline \multirow[t]{5}{*}{ A/duck/Mongolia/543/2015 (H4N6) } & \multirow[t]{5}{*}{ PB2 } & $89 \mathrm{~V}$ & $\mathrm{~L} \rightarrow \mathrm{V}$ & Increased pathogenicity in mice [21] \\
\hline & & 309D & $\mathrm{G} \rightarrow \mathrm{D}$ & Increased virulence and replication in mice [21] \\
\hline & & $339 \mathrm{~K}$ & $\mathrm{~T} \rightarrow \mathrm{K}$ & Increased virulence and replication in mice [21] \\
\hline & & $477 \mathrm{G}$ & $\mathrm{R} \rightarrow \mathrm{G}$ & Increased virulence and replication in mice [21] \\
\hline & & $495 \mathrm{~V}$ & $\mathrm{I} \rightarrow \mathrm{V}$ & Increased virulence and replication in mice [21] \\
\hline \multirow{2}{*}{$\begin{array}{l}\text { A/muscovy duck/Viet Nam/HN-2504/2015 } \\
\text { (H5N6) }\end{array}$} & \multirow[t]{2}{*}{ PB1 } & $99 \mathrm{H}$ & $\mathrm{H} \rightarrow \mathrm{Y}$ & H5 transmissibility in ferrets $[8]$ \\
\hline & & $368 I$ & $\mathrm{I} \rightarrow \mathrm{V}$ & H5 transmissibility in ferrets [8] \\
\hline \multirow[t]{2}{*}{ A/duck/Hokkaido/20/2015 (H3N8) } & PA & $97 \mathrm{~T}$ & $\mathrm{~T} \rightarrow \mathrm{I}$ & $\begin{array}{l}\text { Enhanced polymerase activity; increased virulence } \\
\text { [8] }\end{array}$ \\
\hline & PA-X & $195 \mathrm{R}$ & $\mathrm{R} \rightarrow \mathrm{K}$ & $\begin{array}{l}\text { Increased replication and transmission in ferrets } \\
\text { [23] }\end{array}$ \\
\hline \multirow{3}{*}{$\begin{array}{l}\text { A/muscovy duck/Viet Nam/QN-2612/2016 } \\
\text { (H5N6) }\end{array}$} & \multirow[t]{3}{*}{ NP } & $286 \mathrm{~A}$ & $\mathrm{~A} \rightarrow \mathrm{V}$ & Attenuated the virulence in mice [24] \\
\hline & & $319 \mathrm{~N}$ & $\mathrm{~N} \rightarrow \mathrm{K}$ & Enhanced replication efficiency [25] \\
\hline & & $437 \mathrm{~T}$ & $\mathrm{~T} \rightarrow \mathrm{M}$ & Attenuated the virulence in mice [24] \\
\hline \multirow[t]{3}{*}{ A/duck/Vietnam/HU4-879/2015 (H5N6) } & \multirow[t]{2}{*}{ M1 } & $30 \mathrm{D}$ & $\mathrm{N} \rightarrow \mathrm{D}$ & Increased virulence in mice [8] \\
\hline & & $215 \mathrm{~A}$ & $\mathrm{~T} \rightarrow \mathrm{A}$ & Increased virulence in mice [8] \\
\hline & M2 & $31 \mathrm{~S}$ & $\mathrm{~S} \rightarrow \mathrm{N}$ & Amantadine resistance [26] \\
\hline \multirow[t]{3}{*}{ A/duck/Vietnam/HU4-879/2015 (H5N6) } & \multirow[t]{3}{*}{ NS1 } & $42 \mathrm{~S}$ & $\mathrm{P} \rightarrow \mathrm{S}$ & Increased virulence in mice [8] \\
\hline & & $92 \mathrm{E}$ & $\mathrm{D} \rightarrow \mathrm{E}$ & Increased virulence in mice and pigs [21] \\
\hline & & $\begin{array}{l}80 \rightarrow 84 \text { deletion } \\
\text { ESEV }\end{array}$ & $\begin{array}{l}\text { C-terminal } \\
\text { PDZ-motif }\end{array}$ & $\begin{array}{l}\text { Increased viral virulence in chicken and mice [27] } \\
\text { Increased virulence in mice [21] }\end{array}$ \\
\hline
\end{tabular}

*Amino acid position, $A$ alanine; $D$ aspartic acid; $E$ glutamic acid; $G$ glycine; $H$ histidine; $I$ Isoleucine; $K$ lysine; $L$ leucine; $M$ methionine; $N$ asparagine; $P$ proline; $Q$ glutamine; $R$ arginine; $S$ serine; $T$ threonine, $V$ valine; $Y$ tyrosine 
(A) HA

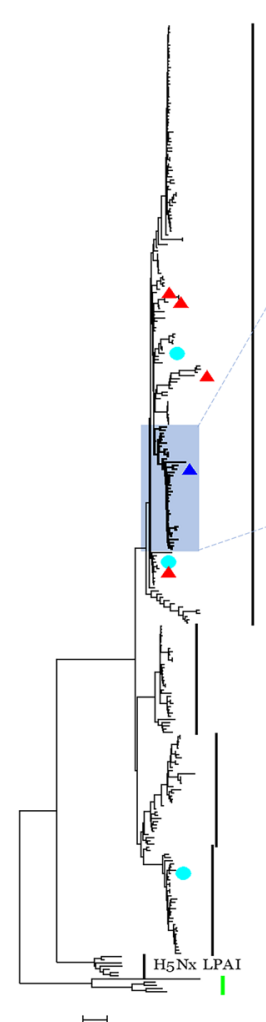

(B) NA

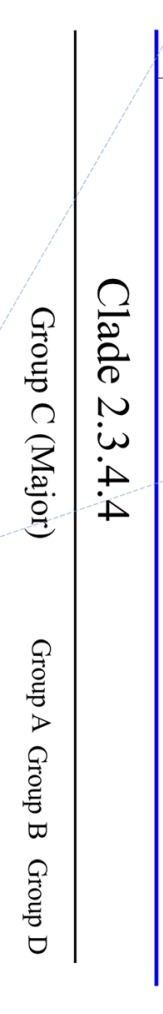



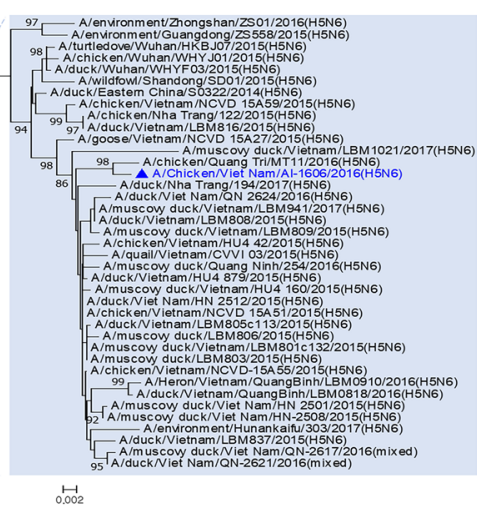

(C) PB2

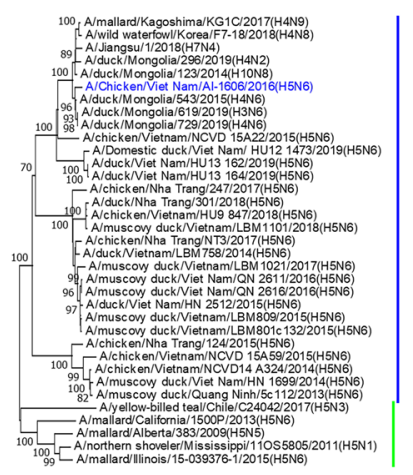

$\stackrel{\bullet}{\circ .02}$

\section{(D) PB1}

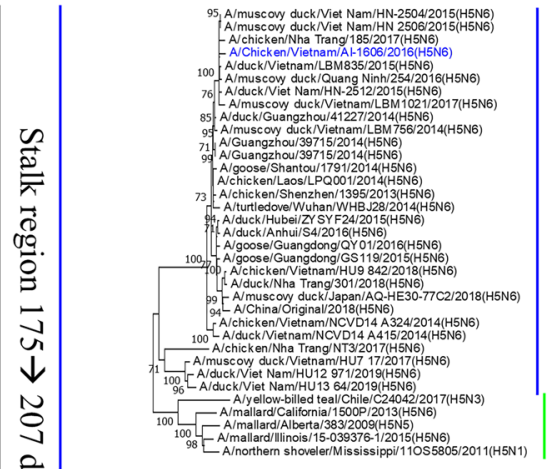

$\stackrel{\leftrightarrow}{\longrightarrow .02}$

(E) PA

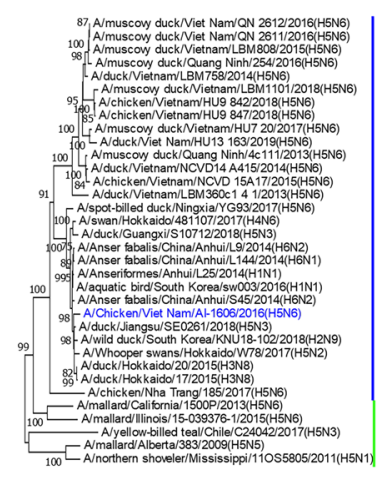

$\mapsto .02$
(F) NP

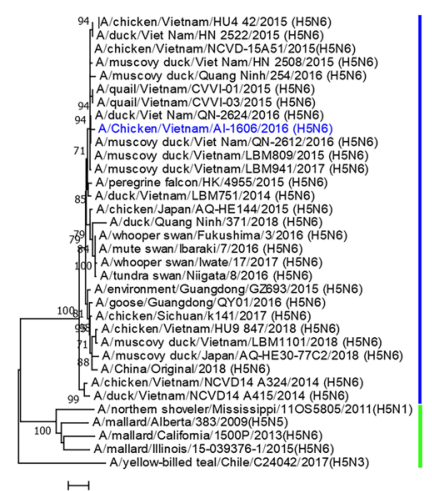

$\stackrel{\longmapsto}{\longmapsto}$

(G) $\mathrm{M}$

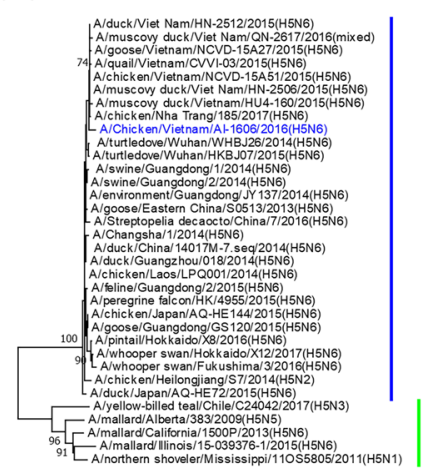

NS

(H) NS

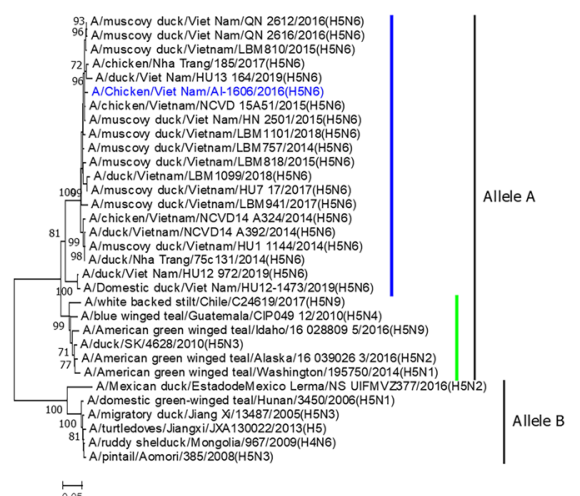

\section{(I) Genotype illustration}

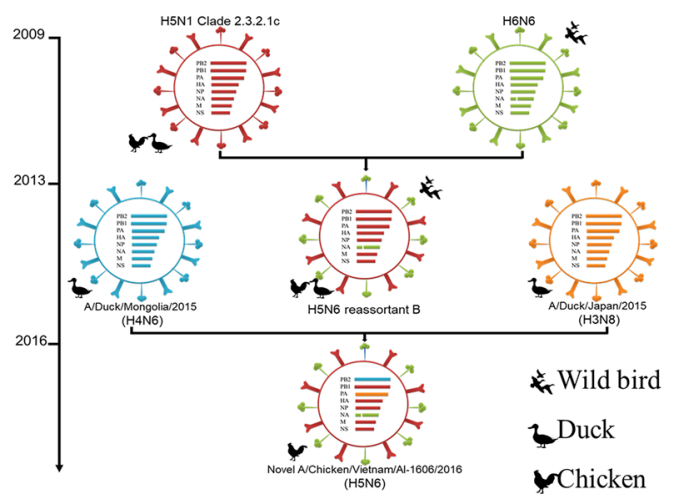


to China and prevalent from 2012 to 2013 [5]. Phylogenetic analysis revealed elaborate genetic linkages of the Vietnam and China clade 2.3.4.4 viruses to clade 2.3.2.1c viruses. The recently isolated A/AI-1606/16 virus was detected in chickens in LPMs where many cases of reassorted AIVs were reported [31]. Interestingly, the PB2 and PA genes of A/AI-1606/16 isolate were found to be closely related to LPAIV strains from ducks in Japan (H3N8) and Mongolia (H4N6), which is a long distance away from Vietnam. We thus hypothesized that the parent gene pool of the Japanese and Mongolian LPAIV strains was possibly transmitted to wild birds which may have interacted with poultry before migrating along the East Asian-Australasian flyway to Vietnam [32]. In particular, free-range duck farms where poultry share water sources with wild waterfowl are very popular in Asian countries hence the high risk of AIV reassortment and transmission [33]. Ducks exhibited notably higher resistance to H5N6 HPAIVs compared to chickens [34]. Therefore, we speculated that the newly isolated A/AI-1606/16 virus might have reassorted in free-ranging poultry management practices in Vietnam, at the intersection of wild birds and the poultry sector, and later presented in LPMs.

Vietnam is also part of the East Asia-Australasian flyway and Thinh et al. [35] showed avian influenza A viruses including $\mathrm{H} 5$ and $\mathrm{H} 6$, and $\mathrm{H} 9$ subtypes were isolated from wild migratory birds in Vietnam. Indeed, a live poultry movement network between Vietnam and other neighboring countries revealed the epidemiological links for AIV importation to Vietnam [36]. For example, the clade 7.1 H5N1 HPAIVs were detected in seized chickens at ports of entry in Lang Son Province, and this clade was also detected in an LPM in the Hai Duong Province [37]. Additionally, an A/Muscovy duck/Long An/AI470/2018 (H5N6) isolate in southern Vietnam shared 99\% homology with the human isolate A/Guangxi/32797/2018 (H5N6) in China (Fig. 1) [38].

Sites of trade and marketing of live poultries are hot spots for AIV transmission, with multiple subtypes of AIVs, including HPAIVs and LPAIVs, having been detected in LPMs [25]. AIVs have also frequently been detected in poultry farms with poor conditions and those that are free-range [39]. This formed a conducive ecosystem for AIV cohabitation in bird populations. Close contact between humans and live poultries provides opportunities for AIVs to cross the species barrier; indeed, most H7N9 infected human cases have a history of exposure to LPMs [40]. In summary, to control zoonosis of AIVs, enhanced feeding biosecurity, strict transport management, and active surveillance must be implemented.

Supplementary Information The online version contains supplementary material available at https://doi.org/10.1007/s00284-021-02661-z.
Acknowledgements We thank the following colleagues of Van Thi Lo (Korea Research Institute of Bioscience and Biotechnology, South Korea) excellent technical assistance and also thank Dr. In-Kyu Kim (Korea Institute of Environment Ecology, South Korea) for informative discussions.

Author Contributions TBL, VPL, JEL, JAK, TBNT, and HWL performed the experiments and analyzed the data. TBL, DGJ, and SWY designed the experiments and wrote the manuscript. All authors have read and agreed to the published version of the manuscript.

Funding This research was supported by grants from the KRIBB Initiative program, supported the BioNano Health-Guard Research Center funded by the Ministry of Science, ICT \& Future Planning (MSIP) of Korea as a Global Frontier Project (Grant No. H-GUARD 2013M3A6B2078954), a National Research Foundation of Korea (NRF) grant funded by the Korean government (No. 2020R1A2C2009262), and a National Research Foundation of Korea (NRF) Grant funded by the Korean government (MSIT) (No. 2020R1A2C2009262).

\section{Declarations}

Conflict of interest The authors declare no conflicts of interest.

Ethical Approval The samples were collected for practical purpose of graduate students in Veterinary Medicine faculty, Vietnam National University of Agriculture (VNUA) with agreement from poultry retailers and farm owners. All animal studies were conducted in the biosafety facility of the College of Veterinary Medicine, VNUA, Hanoi, Vietnam. This experimental study followed the guidelines approved by the Animal Ethics Committee of the VNUA (Approval number, 5112/ QĐ-NNH; Approval date, December 31, 2019).

Open Access This article is licensed under a Creative Commons Attribution 4.0 International License, which permits use, sharing, adaptation, distribution and reproduction in any medium or format, as long as you give appropriate credit to the original author(s) and the source, provide a link to the Creative Commons licence, and indicate if changes were made. The images or other third party material in this article are included in the article's Creative Commons licence, unless indicated otherwise in a credit line to the material. If material is not included in the article's Creative Commons licence and your intended use is not permitted by statutory regulation or exceeds the permitted use, you will need to obtain permission directly from the copyright holder. To view a copy of this licence, visit http://creativecommons.org/licenses/by/4.0/.

\section{References}

1. Yoon SW, Webby RJ, Webster RG (2014) Evolution and ecology of influenza A viruses. Curr Top Microbiol Immunol 385:359375. https://doi.org/10.1007/82_2014_396

2. Sonnberg S, Webby RJ, Webster RG (2013) Natural history of highly pathogenic avian influenza H5N1. Virus Res 178:63-77. https://doi.org/10.1016/j.virusres.2013.05.009

3. Zhang Y, Sun Y, Sun H et al (2012) A single amino acid at the hemagglutinin cleavage site contributes to the pathogenicity and neurovirulence of H5N1 influenza virus in mice. J Virol 86:69246931. https://doi.org/10.1128/jvi.07142-11

4. Antigua KJC, Choi WS, Baek YH et al (2019) The emergence and decennary distribution of clade 2.3.4.4 HPAI H5Nx. Microorganisms. https://doi.org/10.3390/microorganisms7060156 
5. Yang L, Zhu W, Li X et al (2017) Genesis and dissemination of highly pathogenic H5N6 avian influenza viruses. J Virol. https:// doi.org/10.1128/jvi.02199-16

6. Bi Y, Chen Q, Wang Q et al (2016) Genesis, evolution and prevalence of H5N6 avian influenza viruses in China. Cell Host Microbe 20:810-821. https://doi.org/10.1016/j.chom.2016.10.022

7. Chen LL, Huo X, Qi X et al (2020) A fatal paediatric case infected with reassortant avian influenza $\mathrm{A}(\mathrm{H} 5 \mathrm{~N} 6)$ virus in Eastern China. Transbound Emerg Dis. https://doi.org/10.1111/tbed.13561

8. Yu Z, Gao X, Wang T et al (2015) Fatal H5N6 avian influenza virus infection in a domestic cat and wild birds in China. Sci Rep 5:10704. https://doi.org/10.1038/srep10704

9. Li X, Fu Y, Yang J et al (2015) Genetic and biological characterization of two novel reassortant H5N6 swine influenza viruses in mice and chickens. Infect Genet Evol 36:462-466. https://doi.org/ 10.1016/j.meegid.2015.08.017

10. Le TH, Nguyen NT (2014) Evolutionary dynamics of highly pathogenic avian influenza A/H5N1 HA clades and vaccine implementation in Vietnam. Clin Exp Vaccine Res 3:117-127. https://doi. org/10.7774/cevr.2014.3.2.117

11. Wan XF, Nguyen T, Davis CT et al (2008) Evolution of highly pathogenic $\mathrm{H} 5 \mathrm{~N} 1$ avian influenza viruses in Vietnam between 2001 and 2007. Plos One 3:e3462. https://doi.org/10.1371/journ al.pone. 0003462

12. Nguyen T, Rivailler P, Davis CT et al (2012) Evolution of highly pathogenic avian influenza (H5N1) virus populations in Vietnam between 2007 and 2010. Virology 432:405-416. https://doi.org/ 10.1016/j.virol.2012.06.021

13. Nguyen DT, Jang Y, Nguyen TD et al (2017) Shifting clade distribution, reassortment, and emergence of new subtypes of highly pathogenic avian influenza $\mathrm{A}(\mathrm{H} 5)$ viruses collected from Vietnamese poultry from 2012 to 2015. J Virol. https://doi.org/10. 1128/jvi.01708-16

14. Nguyen LT, Stevenson MA, Firestone SM et al (2020) Spatiotemporal and risk analysis of H5 highly pathogenic avian influenza in Vietnam, 2014-2017. Prev Vet Med 178:104678. https://doi.org/ 10.1016/j.prevetmed.2019.04.007

15. Sealy JE, Fournie G, Trang PH et al (2019) Poultry trading behaviours in Vietnamese live bird markets as risk factors for avian influenza infection in chickens. Transbound Emerg Dis 66:25072516. https://doi.org/10.1111/tbed.13308

16. Spackman E, Senne DA, Myers TJ et al (2002) Development of a real-time reverse transcriptase PCR assay for type A influenza virus and the avian $\mathrm{H} 5$ and $\mathrm{H} 7$ hemagglutinin subtypes. J Clin Microbiol 40:3256-3260. https://doi.org/10.1128/jcm.40.9.32563260.2002

17. Le TB, Kim HK, Na W et al (2020) Development of a multiplex RT-qPCR for the detection of different clades of avian influenza in poultry. Viruses. https://doi.org/10.3390/v12010100

18. Yoo HS, Eah JY, Kim JS et al (2006) DNA barcoding Korean birds. Mol Cells 22:323-327

19. Çakmak E, Akın Pekşen Ç, Bilgin CC (2017) Comparison of three different primer sets for sexing birds. J Vet Diagn Invest 29:59-63. https://doi.org/10.1177/1040638716675197

20. Hoffmann E, Stech J, Guan Y et al (2001) Universal primer set for the full-length amplification of all influenza A viruses. Arch Virol 146:2275-2289

21. Shen YY, Ke CW, Li Q et al (2016) Novel reassortant avian influenza A(H5N6) viruses in humans, Guangdong, China, 2015. Emerg Infect Dis 22:1507-1509. https://doi.org/10.3201/eid2208. 160146

22. Samson M, Pizzorno A, Abed Y et al (2013) Influenza virus resistance to neuraminidase inhibitors. Antiviral Res 98:174-185. https://doi.org/10.1016/j.antiviral.2013.03.014

23. Sun Y, Hu Z, Zhang X et al (2020) An R195K mutation in the PA-X protein increases the virulence and transmission of influenza
A virus in mammalian hosts. J Virol. https://doi.org/10.1128/jvi. 01817-19

24. Ma S, Zhang B, Shi J et al (2020) Amino acid mutations A286V and $\mathrm{T} 437 \mathrm{M}$ in the nucleoprotein attenuate $\mathrm{H} 7 \mathrm{~N} 9$ viruses in mice. J Virol. https://doi.org/10.1128/jvi.01530-19

25. Li X, Yang J, Liu B et al (2016) Co-circulation of H5N6, H3N2, H3N8, and emergence of novel reassortant H3N6 in a local community in Hunan Province in China. Sci Rep 6:25549. https://doi. org/10.1038/srep25549

26. Wang J, Wu Y, Ma C et al (2013) Structure and inhibition of the drug-resistant S31N mutant of the M2 ion channel of influenza A virus. Proc Natl Acad Sci USA 110:1315-1320. https://doi.org/ 10.1073/pnas.1216526110

27. Long JX, Peng DX, Liu YL et al (2008) Virulence of H5N1 avian influenza virus enhanced by a 15-nucleotide deletion in the viral nonstructural gene. Virus Genes 36:471-478. https://doi.org/10. 1007/s11262-007-0187-8

28. Hu Y, Musharrafieh R, Ma C et al (2017) An M2-V27A channel blocker demonstrates potent in vitro and in vivo antiviral activities against amantadine-sensitive and -resistant influenza A viruses. Antiviral Res 140:45-54. https://doi.org/10.1016/j.antiviral.2017. 01.006

29. Zhang Y, Chen M, Huang Y et al (2017) Human infections with novel reassortant H5N6 avian influenza viruses in China. Emerg Microbes Infect 6:e50. https://doi.org/10.1038/emi.2017.38

30. Nguyen LT, Firestone SM, Stevenson MA et al (2019) A systematic study towards evolutionary and epidemiological dynamics of currently predominant $\mathrm{H} 5$ highly pathogenic avian influenza viruses in Vietnam. Sci Rep 9:7723. https://doi.org/10.1038/ s41598-019-42638-4

31. Qi X, Cui L, Yu H et al (2014) Whole-genome sequence of a reassortant H5N6 avian influenza virus isolated from a live poultry market in China, 2013. Genome Announc. https://doi.org/10. 1128/genomeA.00706-14

32. Soda K, Kashiwabara M, Miura K et al (2020) Characterization of $\mathrm{H} 3$ subtype avian influenza viruses isolated from poultry in Vietnam. Virus Genes 56:712-723. https://doi.org/10.1007/ s11262-020-01797-7

33. Cappelle J, Zhao D, Gilbert M et al (2014) Risks of avian influenza transmission in areas of intensive free-ranging duck production with wild waterfowl. EcoHealth 11:109-119. https://doi.org/ 10.1007/s10393-014-0914-2

34. Jang Y, Seo SH (2020) Age-dependent lethality in ducks caused by highly pathogenic H5N6 avian influenza virus. Viruses. https:// doi.org/10.3390/v12060591

35. Thinh TV, Gilbert M, Bunpapong N et al (2012) Avian influenza viruses in wild land birds in northern Vietnam. J Wildl Dis 48:195-200. https://doi.org/10.7589/0090-3558-48.1.195

36. Meyer A, Dinh TX, Han TA et al (2018) Trade patterns facilitating highly pathogenic avian influenza virus dissemination in the free-grazing layer duck system in Vietnam. Transbound Emerg Dis 65:408-419. https://doi.org/10.1111/tbed.12697

37. Davis CT, Balish AL, O'Neill E et al (2010) Detection and characterization of clade 7 high pathogenicity avian influenza H5N1 viruses in chickens seized at ports of entry and live poultry markets in Vietnam. Avian Dis 54:307-312. https://doi.org/10.1637/ 8801-040109-ResNote.1

38. Tsunekuni R, Sudo K, Nguyen PT et al (2019) Isolation of highly pathogenic H5N6 avian influenza virus in Southern Vietnam with genetic similarity to those infecting humans in China. Transbound Emerg Dis 66:2209-2217. https://doi.org/10.1111/tbed.13294

39. Karlsson EA, Horm SV, Tok S et al (2019) Avian influenza virus detection, temporality and co-infection in poultry in Cambodian border provinces, 2017-2018. Emerg Microbes Infect 8:637-639. https://doi.org/10.1080/22221751.2019.1604085 
40. Wang C, Wang J, Su W et al (2014) Relationship between domestic and wild birds in live poultry market and a novel human H7N9 virus in China. J Infect Dis 209:34-37. https://doi.org/10.1093/ infdis/jit478
Publisher's Note Springer Nature remains neutral with regard to jurisdictional claims in published maps and institutional affiliations. 